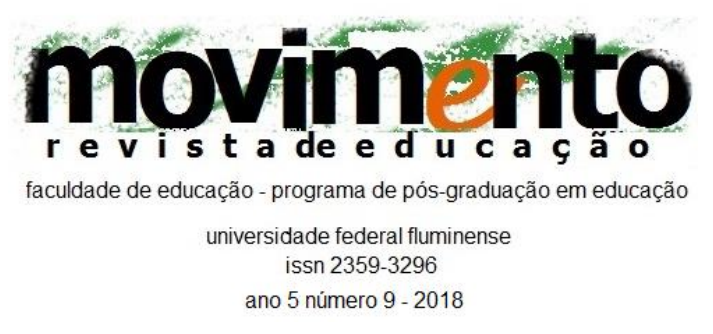

\title{
EDUCAÇÃO SUPERIOR NO BRASIL: permanência de estudantes e rentabilidade do setor privado
}

\author{
Marco Aurelio Nunes de Barros \\ Universidade Federal Fluminense, \\ Niterói, RJ, Brasil \\ Hildete Pereira de Melo Hermes de Araujo \\ Universidade Federal Fluminense, \\ Niterói, RJ, Brasil
}

\begin{abstract}
Resumo
A compreensão do fenômeno da permanência na educação superior vem crescendo, porém há poucos estudos sobre o papel das IES privadas. $O$ artigo discute a importância da análise dessas empresas no Brasil e qual a sua relação com esse tema. Foi feita pesquisa exploratória, partindo de dados oficiais, estudo de casos e da construção de um modelo teórico para análise das ações das organizações privadas. Os achados indicam uma mudança residual nas políticas de permanência nas IES privadas e se propõe o incremento dos estudos sobre o setor privado no desenho de políticas para a permanência dos estudantes.

Palavras-Chave: Educação superior; Permanência no ensino; Setor privado.
\end{abstract}

\section{HIGHER EDUCATION IN BRAZIL: permanence of students and private sector profitability}

\begin{abstract}
:
The understanding of phenomenon of permanence in higher education has been growing, but there are few studies about role of private HEls. The article discusses analysis of role of higher education companies in Brazil in that issue. Exploratory research was done, based on official data, case studies, and construction of a theoretical model to analyze the actions of private organizations. The findings indicate a residual change in the policies of permanence in the private HEls and it is proposed to increase studies on the private sector, in the design of policies for permanence of the students.

Keywords: Higher education; Permanence in learning; Private sector.
\end{abstract}




\title{
movimento \\ faculdade de educação - programa de pós-graduação em educação \\ universidade federal fluminense \\ issn 2359-3296 \\ ano 5 número 9 - 2018
}

\section{EDUCACIÓN SUPERIOR EN BRASIL: permanencia de estudiantes y rentabilidad del sector privado}

\begin{abstract}
Resumén
Los estudios del fenómeno de la permanencia en la educación superior vienen aumentando, pero hay pocos sobre el papel de las IES privadas. El artículo analiza el papel de las empresas de educación superior en Brasil en ese tema. Se hizo una pesquisa exploratoria, basada en datos oficiales, estudios de casos y en empleo de modelo teórico para analizar acciones de las IES privadas. Los hallazgos indican un cambio residual en las políticas de permanencia en las IES privadas. Se propone ampliar los estudios en el sector privado, en el diseño de políticas para la permanencia de los estudiantes.

Palabras clave: Educación universitaria; Permanencia en el aprendizaje; Sector privado.
\end{abstract}

\section{Introdução}

A educação superior passou a ocupar um novo e destacado lugar na organização das forças produtivas no mundo contemporâneo. As mudanças iniciadas a partir dos anos 1970, intensificadas com a reestruturação produtiva, e estendidas até hoje transformaram as forças econômicas e sociais nos diferentes recantos do planeta ${ }^{1}$.

conhecimento, a ciência e a tecnologia passaram a desempenhar um papel ainda mais central na produção e na distribuição desigual de riquezas e bens produzidos social e simbolicamente nessas sociedades. O conhecimento tornou-se uma mercadoria fetichizada e que fetichiza, inclusive os seus espaços de produção. ${ }^{2}$

\footnotetext{
1 Diferentes aspectos dessas transformações podem ser identificados em: Bell (1977), Arrighi (1996), Andrade (2002) e Atkinson (2015).

${ }^{2}$ Essa fetichização corresponde à crença de que o desenvolvimento é um processo autônomo frente às relações de produção e a tecnologia pode determinar o movimento histórico de transformação social, como algo com "um sentido único e inexorável", como se os seres
} 


\section{movimento \\ faculdade de educação - programa de pós-graduação em educação \\ universidade federal fluminense \\ issn 2359-3296 \\ ano 5 número 9 - 2018}

As dramáticas mudanças políticas, sociais e culturais que vêm ocorrendo na organização e na manutenção da vida e nas relações entre pessoas afetaram tanto a esfera pública quanto a existência privada dos indivíduos nessas sociedades. Além disso, elas impuseram transformações não apenas ao mundo do trabalho e aos valores pessoais, mas às instituições universitárias também.

Sguisardi (2015) indica as ameaças ao papel e a identidade das instituições universitárias nesse contexto contraditório, no qual se tenta reduzir a universidade a uma mera organização que oferece um serviço a quem possa usufruí-lo:

Jamais como hoje a universidade foi pensada como parte da economia. Jamais como hoje o conhecimento, a ciência e a tecnologia foram tão valorizados como mercadoria capital a ser apropriada hegemonicamente pelas grandes corporações globalizadas e no interesse dos países centrais. Se o diagnóstico neoliberal aponta a falta de competitividade como a grande fragilidade da economia, na crise do Estado do Bem-Estar, é essa característica-chave da empresa econômica e do mercado que, aos poucos, vai se implantando na universidade e tornando-se constitutiva de sua identidade. A ideia de uma universidade organizada e gerida nos moldes empresariais, trabalhando com uma semimercadoria no quase-mercado educacional está cada vez mais presente no discurso e nas práticas oficiais das políticas públicas de educação superior. (p.215).

Apesar de apoiar-se nas noções aparentemente frágeis de semimercadoria e de quase-mercado ${ }^{3}$ como elementos centrais da sua análise, a visão de Sguisardi (2005) possibilita uma perspectiva crítica sobre o processo de

humanos não fossem os atores de sua própria história. A esse respeito, veja: Silveira (2011, p. 69-75) e, também, Paz e Bezerra (2007) e Mancebo (2004).

${ }^{3}$ As categorias quase-mercado e semimercadoria parecem ignorar que um setor econômico que representa, só entre as organizações privadas, uma produção de receitas superiores a cinquenta bilhões de reais ao ano. Ainda que não se goste dessa ideia e se deva lutar pela educação pública, universal e de qualidade, a educação superior é um imponente mercado no Brasil, financiado inclusive com dinheiro público. Cabe ainda a ressalva de que essas categorias têm sua origem em trabalhos de pesquisadores portugueses onde o sistema universitário é bem distinto do brasileiro. 


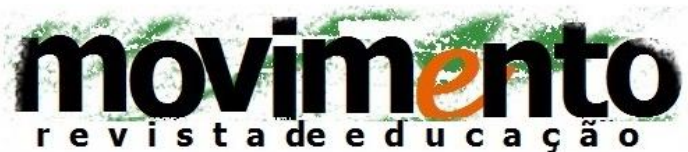 \\ faculdade de educação - programa de pós-graduação em educação \\ universidade federal fluminense \\ issn 2359-3296 \\ ano 5 número 9 - 2018}

transformação pelo qual passa a universidade e sobre as relações tensas e contraditórias que a oferta de um bem público como mercadoria produz nas diferentes sociedades.

No mundo, dentre os diferentes aspectos afetados por esse processo, destacam-se a introdução de uma nova cultura competitiva global por alunos, o crescente endividamento dos estudantes e a financeirização das atividades educacionais ${ }^{4}$.

O caso norte-americano é um exemplo de como isso pode reforçar as desigualdades sociais. Armstrong e Hamilton (2015), após um estudo longitudinal demonstraram que a promoção de estratégias de manutenção de alunos baseados em atividades como a realização de festas e eventos que nada contribuem para sua formação reforçaram as desigualdades sociais existentes, em especial a desigualdade de gênero.

No Brasil, muitos são os desafios que a universidade enfrenta nesse cenário marcado pelas reformas de caráter neoliberal. Os instrumentos regulatórios propõem a ampliação da oferta de vagas, mas sendo elas advindas de empresas de educação de propriedade dos grupos empresariais brasileiros e/ou estrangeiros. Dessa forma, são esses empresários que disputam o fundo público nos processos de privatização e de mercantilização da educação.

Prestigiando as práticas, as metodologias, as filosofias e as concepções da realidade do setor privado, ao invés de se construírem alternativas sólidas de resolução para problemas como a garantia de acesso e a permanência, a oferta da educação gratuita e socialmente referenciada e a promoção da

\footnotetext{
${ }^{4}$ Sobre o processo de transformações, reformas e contrarreformas da educação superior e reconfiguração da universidade, em nível internacional, sugere-se, ver Silveira (2011) e Silveira e Bianchetti (2016).
} 


\section{movimento \\ faculdade de educação - programa de pós-graduação em educação \\ universidade federal fluminense \\ issn 2359-3296 \\ ano 5 número 9 - 2018}

qualidade de ensino se impõem ainda como novos desafios para os sistemas universitários.

Nas políticas de expansão da educação superior implementadas desde a década de 1990, os incentivos à atuação de organizações privadas crescem tanto para as entidades confessionais e as comunitárias quanto para as organizações privadas propriamente ${ }^{5}$ ditas. 0 impacto dessas políticas na ampliação da oferta na educação superior latino-americana foi tão significativo que provocou uma mudança do panorama em toda a região. ${ }^{6}$

Essa mudança fica evidente no crescimento das matrículas: 17\% em 1991 para 40\% em 2010. Foram criadas nesse período mais de 2.300 instituições de educação superior e mais de 30.000 novos cursos: cerca de um quarto dos estabelecimentos de ensino e metade dos cursos passaram a existir após o ano de 1990.

Apenas no México e na Colômbia, a participação do setor privado na distribuição das matriculas não aumentou em relação ao setor público. Na República Dominicana e em El Salvador, essa participação permaneceu praticamente estável nesse mesmo período. Nos demais países, a presença desse setor tornou-se ainda maior (Figura 1). Mesmo onde ele já era muito representativo - Chile e Brasil - houve inclusive o ingresso de capitais internacionais via mercado de capitais e aquisição de IES locais.

\footnotetext{
${ }^{5}$ Apesar de se poder dizer que todas as organizações privadas visam ao lucro, poucos países formalizaram em seus sistemas universitários, esse tipo de modalidade de organização e possibilitaram-Ihes condições para acesso ao mercado de capitais, distinguindo-as daquelas que têm outras finalidades declaradas: as filantrópicas e as confessionais. Nesse sentido, 0 caso brasileiro é singular.

${ }^{6}$ Segundo o relatório "Numa encruzilhada: O Ensino superior na América Latina e no Caribe" publicado pelo Banco Mundial em 2017. Maiores informações em Ferreyra (2017).
} 


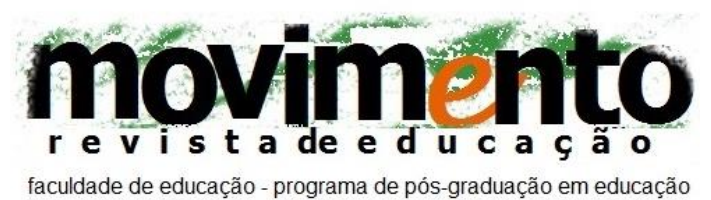

universidade federal fluminense

issn 2359-3296

ano 5 número 9 - 2018

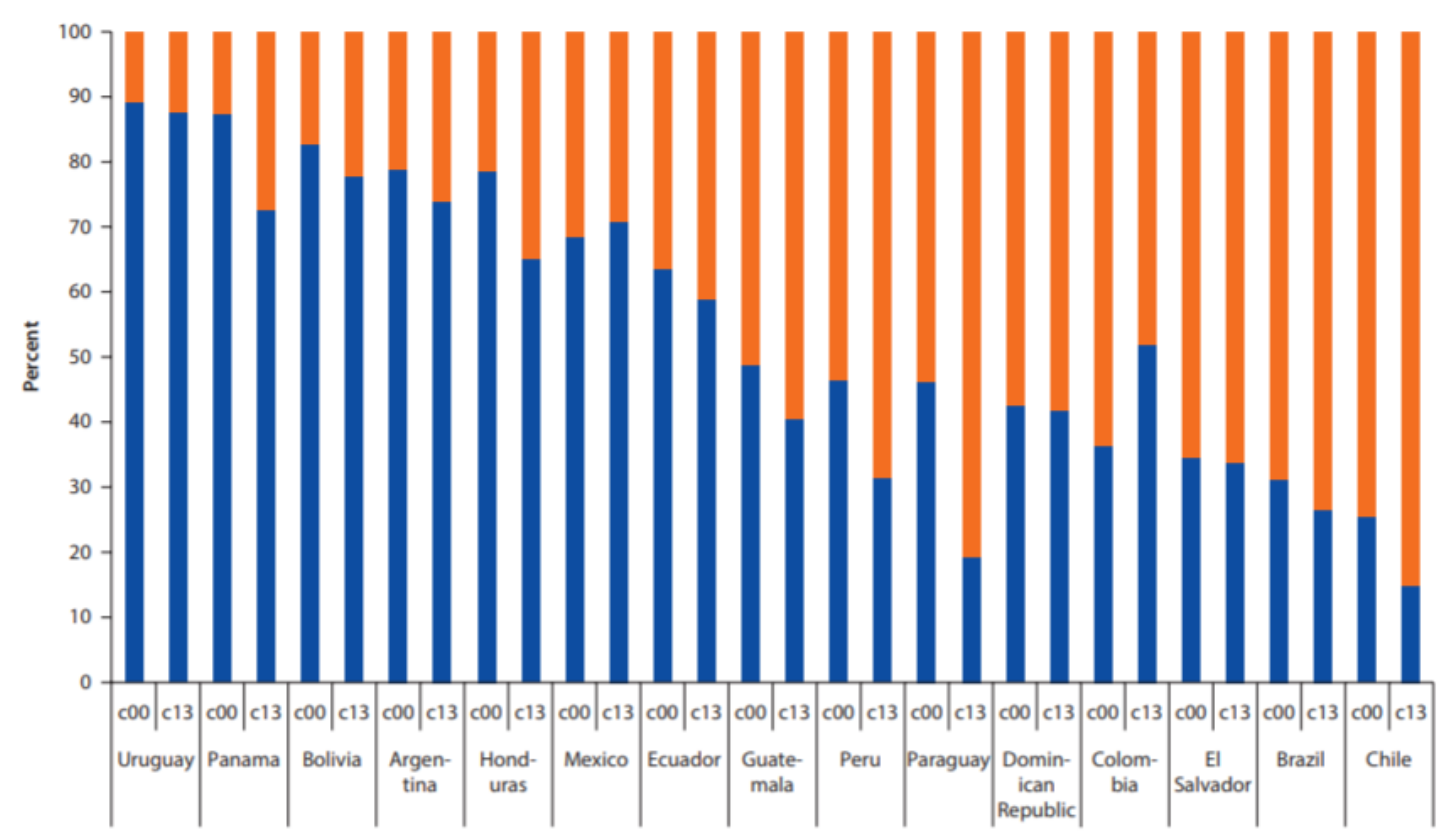

Public $\square$ Private

Figura 1: Percentual das matrículas em IES Públicas e Privadas, América Latina e Caribe, 2000 e 2013. Fonte: Banco Mundial, 2017.

Na tabela 1, é possível observar a evolução na oferta total de matrículas no Brasil. Fica evidente a participação das instituições privadas em cursos de graduação presenciais a partir dos anos de 1990.

\begin{tabular}{lccccc}
\hline \multirow{2}{*}{ Ano } & \multicolumn{3}{c}{ Pública } & \multicolumn{3}{c}{ Privada } & \multirow{2}{*}{ Total } \\
\cline { 2 - 3 } \cline { 5 - 6 } & Matriculas & Total (\%) & Matriculas & Total (\%) & \\
\hline 1960 & 59.624 & 58,6 & 47.067 & 41,4 & 101.691 \\
1970 & 210.613 & 49,5 & 214.865 & 50,5 & 425.478 \\
1980 & 492.232 & 35,7 & 885.054 & 64,3 & 1.377 .286 \\
1990 & 578.625 & 37,6 & 961.455 & 62,4 & 1.540 .080 \\
2000 & 887.026 & 32,9 & 1.807 .219 & 67,1 & 2.694 .245 \\
2010 & 1.461 .696 & 26,8 & 3.987 .424 & 73,2 & 5.449 .120 \\
\hline
\end{tabular}

Tabela 1: Evolução das matrículas em cursos de graduação presenciais, segundo a natureza institucional - Brasil (1960-2010). Fonte: Corbucci, Kubota e Meira (2016, p. 8).

Essa política de expansão foi promovida por diferentes estratégias e instrumentos que criaram condições propícias ao setor privado, tais como: a mudança na composição do Conselho Nacional de Educação, a regularização e a organização da educação a distância, a regulamentação dos centros 


\section{movimento \\ faculdade de educação - programa de pós-graduação em educação \\ universidade federal fluminense \\ issn 2359-3296 \\ ano 5 número 9 - 2018}

universitários, a criação dos instrumentos de reconhecimento da atividade de ensino como um negócio, as mudanças nos mecanismos de regulação, supervisão e avaliação das instituições e dos cursos.

Outros fatores importantes foram a redução das verbas para instituições públicas, as mudanças e a expansão do modelo de financiamento estudantil público e a redução da ociosidade de vagas nas instituições privadas remuneradas com verba governamental. Nesse ponto, destacam-se 0 Programa Universidade para Todos (ProUni) e o Fundo de Financiamento ao Estudante de Ensino Superior (Fies). Em 2014, ambos respondiam por quase $60 \%$ dos ingressantes nas instituições privadas (ver Tabela 2).

\begin{tabular}{lrrrrrrrrrr}
\hline & \multicolumn{1}{c}{2005} & \multicolumn{1}{c}{2006} & \multicolumn{1}{c}{2007} & \multicolumn{1}{c}{2008} & \multicolumn{1}{c}{2009} & \multicolumn{1}{c}{2010} & 2011 & \multicolumn{1}{c}{2012} & \multicolumn{1}{c}{2013} & 2014 \\
\hline ProUni & 95.580 & 109.018 & 105.574 & 124.622 & 161.369 & 152.734 & 170.765 & 176.757 & 177.324 & 223.579 \\
Fies & 77.212 & 58.741 & 49.049 & 32.384 & 32.654 & 71.611 & 153.570 & 368.841 & 557.192 & 732.243 \\
Total & 172.792 & 167.759 & 154.623 & 157.006 & 194.023 & 224.345 & 324.335 & 545.598 & 734.516 & 955.822 \\
Ingressantes & 1.108 .600 & 1.151 .102 & 1.183 .464 & 1.198 .506 & 1.157 .057 & 1.181 .650 & 1.260 .257 & 1.508 .295 & 1.494 .490 & 1.658 .350 \\
ProUni_Fies/Ingressantes & 15,6 & 14,6 & 13,1 & 13,1 & 16,8 & 19,0 & 25,7 & 36,2 & 49,1 & 57,6
\end{tabular}

Tabela 2: Bolsas do ProUni e contratos do Fies concedidos e número de ingressantes em cursos de graduação presenciais nas IES privadas - Brasil (2005-2014). Fonte: Corbucci, Kubota e Meira (2016, p. 8).

No caso brasileiro, essa mudança de panorama tem representado um conjunto novo de questões que os educadores vêm vivenciando. Como exemplo, podemos pensar o enfrentamento à evasão e ao desnível no aprendizado trazido do ensino médio por boa parcela dos ingressantes e a necessária formulação e execução de políticas de permanência na universidade para aqueles alunos que representam uma nova população universitária.

As questões apontadas acima também estão ligadas ao desafio da promoção da qualidade de educação em um contexto de precarização das atividades docentes, de retração de investimentos no setor público e da aplicação de um taylorismo formal e irracional das atividades educativas no setor privado. 


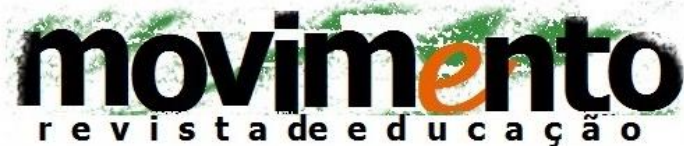 \\ faculdade de educação - programa de pós-graduação em educação \\ universidade federal fluminense \\ issn 2359-3296 \\ ano 5 número 9 - 2018}

A finalidade deste estudo é analisar o significado desses aspectos em relação à evasão e à permanência a partir da atuação do setor privado no enfrentamento aos desafios psicopedagógicos desses estudantes que não são apenas do interesse dos educadores e das instituições que atuam no setor público, mas da sociedade em geral.

\section{O setor privado da educação superior no Brasil}

O setor privado no Brasil corresponde a cerca de 3/4 da oferta de matrículas em educação superior e mais de quatro quintos das instituições universitárias em atividade no país: das 313 escolas de Medicina, 181, ou seja, 57,84\% são particulares. Dados do último Resumo Técnico do Censo da Educação Superior do INEP indicam que esse setor foi responsável por $75,53 \%$ dos concluintes e por $70,4 \%$ dos ingressantes. A tabela 3 mostra essa supremacia nos anos 2013/15.

\begin{tabular}{|c|c|c|c|c|}
\hline \multirow{2}{*}{ Ano } & \multicolumn{3}{|c|}{ Categoria Administrativa } \\
\cline { 2 - 4 } & \multicolumn{3}{|c|}{ Pública } & \multirow{2}{*}{ Privada } \\
\cline { 2 - 4 } & Federal & Estadual & Municipal & \\
\hline 2013 & $4,4 \%$ & $5,0 \%$ & $3,2 \%$ & $87,4 \%$ \\
\hline 2014 & $4,5 \%$ & $5,0 \%$ & $3,1 \%$ & $87,4 \%$ \\
\hline 2015 & $4,5 \%$ & $5,1 \%$ & $2,9 \%$ & $87,5 \%$ \\
\hline
\end{tabular}

Tabela 3: Evolução percentual do número de instituições de educação superior, por categoria administrativa -2013/2015. Fonte: INEP/MEC, 2018, elaboração dos autores ${ }^{7}$

Uma forte ampliação ocorreu nas últimas três décadas e esse crescimento foi liderado indiscutivelmente pelo setor privado, que, apesar de se apresentar como representante de processos educacionais inovadores, está presente na

$\overline{7}$ Dados calculados a partir do Resumo Técnico: Censo da Educação Superior 2015. 


\section{movimento \\ faculdade de educação - programa de pós-graduação em educação \\ universidade federal fluminense \\ issn 2359-3296 \\ ano 5 número 9 - 2018}

educação superior desde a formação do estado brasileiro. No primeiro Império (Pedro I), já havia uma relação ambígua, meandrosa, desigual e combinada entre o público e o privado. ${ }^{8}$

O setor privado da educação superior apresenta-se amplo e diversificado, incluindo variadas formas administrativas: instituições comunitárias, confessionais e filantrópicas, sendo as últimas as que representam as estruturas mais tradicionais desse tipo de instituição. ${ }^{9}$

O segmento pode ser dividido em dois grupos: as instituições particulares e as privadas. Estas teriam um formato societário instituído por contrato social e seriam aquelas cuja finalidade de obtenção de lucro está definida em seus objetivos. Esse texto analisa as estratégias dessas últimas organizações, ou seja, as empresas do setor de educação superior no Brasil.

Essas instituições são empresas e grupos empresariais com títulos e ações negociados na B3 (Bolsas de Valores do Brasil) e no mercado internacional. As mais conhecidas e fortes são as dos grupos Kroton S/A e Estácio Participações $\mathrm{S} / \mathrm{A}$. Elas são líderes na oferta de vagas e também negociam as suas ações na New York Stock Exchange (NYSE) e a Laureate que opera na National Association of Securities Dealers Automated Quotations (NASDAQ).

Segundo Caleffi (2017), os grupos educacionais são aquelas organizações que se constituem como corporações econômicas do segmento educacional. Como tal, elas precisam ser controladoras de diferentes instituições mantenedoras e

\footnotetext{
${ }^{8}$ Sobre as relações históricas entre o público e o privado na educação superior brasileira, ver Cunha 2004, 2007 e 2007a, Durhan, 2005, Brock \& Schwartzman, 2005.

${ }^{9}$ Segundo a organização acadêmica, as IES podem ser universidades, centros universitários, faculdades.
} 


\section{movimento \\ faculdade de educação - programa de pós-graduação em educação \\ universidade federal fluminense \\ issn 2359-3296 \\ ano 5 número 9 - 2018}

possuírem captação de investimento por operação em bolsa de valores ou outros instrumentos financeiros de capitalização.

Como sociedades de capital aberto, elas atuam na busca de rentabilizar lucros, juros e dividendos, além de distribuir bônus para os seus executivos, o que, para muitos educadores, confronta-se com o papel da educação definido na Constituição Federal de 1988, como um bem público ${ }^{10}$.

[...] caber-Ihe-ia o qualificativo de uma política de massificação mercantil? Ou a afirmação de estar pondo em prática uma concepção de ES que confunde educação superior, como direito ou "serviço público", com "serviço comercial" ou mercadoria? De não ser uma política social autônoma, mas a cada dia mais dependente dos interesses do mercado? De continuar a implementar a expansão de uma educação de elite e de alta "qualidade" para poucos e uma educação de massa e de baixa "qualidade" para muitos? (SGUISSARDI, 2015, p. 885).

Para Sguissardi (2015), parece não haver ainda um consenso de que o rumo assumido pela educação superior no Brasil seja uma antítese da democratização do acesso e que tenha se configurado apenas como a consolidação de um mercado privado voltado exclusivamente para a produção e para a apropriação de lucro.

Certamente os dados e as observações visando interpretá-los postos até aqui não permitem respostas conclusivas a nenhuma das questões acima reiteradas, mas permitem pôr em questão, do ponto de vista da democratização que pressupõe o máximo de igualdade de condições, a atual política de expansão da ES no Brasil. Permitem que - com base na distribuição e evolução do número de instituições e matrículas públicas e privadas, especialmente particulares ou privado-mercantis; na concentração por área de conhecimento, por turnos de estudo; nas condições de acesso e permanência; na maior ou menor "exclusão dos incluídos"; e no processo de mercadização/mercantilização etc. - se possa levantar tais questões de forma bastante consistente. (p. 885).

${ }^{10}$ Ver também Sampaio, 2000, Prates, 2014 e Sousa, 2015. 


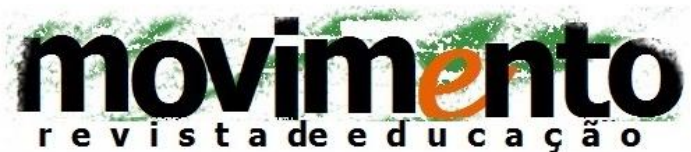 \\ faculdade de educação - programa de pós-graduação em educação \\ universidade federal fluminense \\ issn 2359-3296 \\ ano 5 número 9 - 2018}

No entanto, vários indicadores apontam para a concentração das matrículas em algumas poucas instituições. Segundo relatórios de analistas de consultorias como a Hopper Educação, os dez maiores grupos educacionais KROTON S.A., ESTACIO PARTICIPAÇÕES S/A, LAUREATE INTERNATIONAL UNIVERSITIES, SER EDUCACIONAL S/A, UNIP, UNINOVE, CRUZEIRO DO SUL, ANIMA S/A, DEVRY EDUCATION GROUP e UNICESUMAR ${ }^{11}$ - responderam sozinhos por $42,33 \%$ de todas as matrículas em 2016.

Esses dados parecem indicar que quaisquer medidas que envolvam decisões sobre os rumos da educação superior no Brasil não podem prescindir de considerar a participação das empresas nos processos de formulação, de execução e de avaliação das políticas, mesmo que se considere um contexto de disputa de propostas e de projetos que, hipoteticamente, marca uma sociedade democrática e poliárquica, ${ }^{12}$ como bem definiu Dahl (2005).

Entretanto, apesar dos números expressivos na ampliação das matrículas e da alta competitividade por alunos entre as IES privadas, a preocupação com a permanência dos estudantes não parece ser objeto de políticas consistentes e continuadas dessas instituições. Afinal, além de serem escassos na literatura trabalhos sobre programas e projetos voltados para esse problema, a maioria trata dessa questão apenas como um efeito adverso sobre o fluxo de caixa e

11 KROTON S/A, ESTACIO PARTICIPAÇÕES S/A, LAUREATE INTERNATIONAL UNIVERSITIES, SER EDUCACIONAL S/A, ANIMA S/A e DEVRY EDUCATION GROUP são os nomes das corporações que gerenciam as IES: Universidade Cruzeiro do Sul, Universidade Paulista (UNIP), Universidade Nove de Julho (UNINOVE), Centro Universitário de Maringá (UNICESUMAR), além de serem grupos empresariais, estes são também instituições universitárias.

12 Entendida como a condição de disputas em que nenhum dos participantes dos processos decisórios de uma arena política ou de uma política pública possa ter o protagonismo exclusivo das ações e a hegemonia das decisões e, tão pouco, ser as beneficiárias exclusivas ou privilegiadas dos resultados das políticas. 


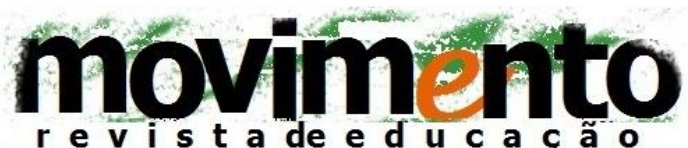 \\ faculdade de educação - programa de pós-graduação em educação \\ universidade federal fluminense \\ issn 2359-3296 \\ ano 5 número 9 - 2018}

neles o discurso se circunscreve apenas às estimativas das perdas de receita potencial.

Outro elemento a ser discutido sobre a importância das políticas de permanência dos estudantes se refere ao número de contratos do FIES entre 2005 e 2014. Apesar de eles terem crescido 850\%, o aumento das matrículas foi de apenas 50\%. Esses dados parecem indicar que a concepção predominante sobre a permanência de estudantes na educação superior esteja reduzida à capacidade de os discentes manterem o fluxo do pagamento de mensalidades.

Quando analisada a relação entre os gastos realizados com o Fies e o crescimento das matrículas no setor privado, verifica-se que as curvas de expansão não têm sido equivalentes entre si, o que sugere que:

[...] proporção significativa dos estudantes que já estavam matriculados tornouse beneficiária do programa, especialmente a partir das mudanças nas condições de financiamento, introduzidas em 2010. Nesse sentido, os impactos da ampliação do Fies estariam mais associados à manutenção da frequência de estudantes e a conclusão dos cursos do que propriamente à ampliação do acesso a um contingente maior de pessoas. (CORBUCCI, KUBOTA E MEIRA, 2016, p. 12).

Na maioria das IES privadas, aspectos como o apoio psicopedagógico e as estratégias voltadas para o enfrentamento e para as questões como a falta de acompanhamento e de orientação aos estudantes em início de curso são considerados como secundários de suas práticas na execução dos projetos de curso. Além disso, dá-se muito pouca importância à constituição de mecanismos para se combater o déficit de conhecimentos herdados do ensino médio e a outras questões que afetam a permanência do discente. Por outro lado, já há algumas experiências de enfrentamento ao tema sendo desenvolvidas por IES privadas e que serão analisadas a seguir. 


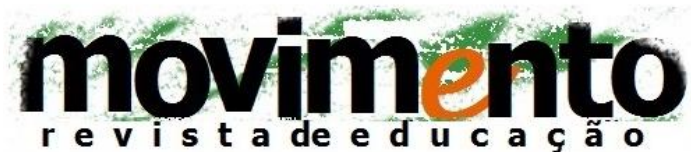 \\ faculdade de educação - programa de pós-graduação em educação \\ universidade federal fluminense \\ issn 2359-3296 \\ ano 5 número 9 - 2018}

Se, por um lado, as políticas para educação superior não podem ignorar a presença e a representatividade do setor privado, por outro, não devem ser submissas e subordinadas aos interesses desse segmento para obtenção de resultados financeiros. Além disso, não podem ter preferência no acesso a recursos públicos subsidiados para expansão de suas atividades, quando em concorrência direta com as instituições públicas.

\section{O que importa é a rentabilidade!}

Para esse trabalho, o desdobramento mais importante do debate sobre dinâmica da educação no Brasil é a discussão sobre o acesso e a permanência na educação superior de estudantes cujas condições pessoais criaram interdições em suas trajetórias de vida. $O$ foco é analisar os motivos que os impossibilitam de usufruir de uma efetiva dedicação ao estudo. Por outro lado, pensar em formas de garantir-Ihes alimentação, descanso e lazer adequados, para, assim, progredirem em seu desenvolvimento pessoal, tão necessário a uma educação superior de qualidade.

De modo geral, os aspectos culturais em que está inserido o núcleo familiar do estudante servem para avaliar a importância dada ao seu novo status social e intelectual. Eventualmente, eles podem surgir como interdições objetivas aos estudos dos discentes, como a cobrança dos benefícios materiais esperados pela dedicação aos estudos, algo que nem sempre se realiza ou se expressa de forma tão objetiva. Além disso, exige-se desse perfil de alunado que a sua vida acadêmica seja finalizada no menor tempo possível.

Segundo dados do CEDLAS (Centro de Estudios Distributivos, Laborales y Sociales), da Universidade Nacional de La Plata, apresentados na tabela 4, no 


\section{movimento \\ faculdade de educação - programa de pós-graduação em educação \\ universidade federal fluminense \\ issn 2359-3296 \\ ano 5 número 9 - 2018}

período de 2000 a 2013, o Brasil registrou o crescimento mais expressivo no ingresso de estudantes universitários oriundos dos dois quintis ${ }^{13}$ mais baixo da distribuição de renda entre os países da América Latina e Caribe.

\begin{tabular}{|l|c|c|c|c|}
\hline \multirow{2}{*}{\multicolumn{1}{c|}{ Países }} & \multicolumn{4}{c|}{ Quintis de renda } \\
\cline { 2 - 5 } & $1 \%$ & $2^{\circ}$ & $4^{\circ}$ & $5^{\circ}$ \\
\hline Argentina & $139 \%$ & $67 \%$ & $-27 \%$ & $-31 \%$ \\
\hline Bolivia & $100 \%$ & $153 \%$ & $-4 \%$ & $-39 \%$ \\
\hline Brasil & $342 \%$ & $318 \%$ & $34 \%$ & $-41 \%$ \\
\hline Chile & $166 \%$ & $132 \%$ & $-24 \%$ & $-37 \%$ \\
\hline Colombia & $0 \%$ & $76 \%$ & $15 \%$ & $-36 \%$ \\
\hline Costa Rica & $110 \%$ & $59 \%$ & $3 \%$ & $-25 \%$ \\
\hline República Dominicana & $46 \%$ & $14 \%$ & $-8 \%$ & $-13 \%$ \\
\hline Equador & $27 \%$ & $40 \%$ & $1 \%$ & $-21 \%$ \\
\hline El Salvador & $47 \%$ & $72 \%$ & $30 \%$ & $-25 \%$ \\
\hline Guatemala & $46 \%$ & $350 \%$ & $-15 \%$ & $-5 \%$ \\
\hline Honduras & $-12 \%$ & $132 \%$ & $14 \%$ & $-8 \%$ \\
\hline Mexico & $77 \%$ & $49 \%$ & $0 \%$ & $-28 \%$ \\
\hline Panama & $37 \%$ & $76 \%$ & $-12 \%$ & $-10 \%$ \\
\hline Paraguai & $227 \%$ & $166 \%$ & $1 \%$ & $-32 \%$ \\
\hline Peru & $113 \%$ & $36 \%$ & $-3 \%$ & $-21 \%$ \\
\hline Uruguai & $7 \%$ & $16 \%$ & $6 \%$ & $-7 \%$ \\
\hline
\end{tabular}

Tabela 4: Evolução dos percentuais de estudantes da educação superior por quintis de renda entre 2000 e 2013. Fonte: CEDLAS/UNLP, elaboração dos autores.

Esses estudantes são justamente aqueles que apresentam inúmeras dificuldades pessoais para concluírem seus estudos. Eles estão sob o risco de abandonarem a universidade, o que tem indiretamente pressionado os educadores e os governos a refletirem sobre a necessidade de desenvolvimento de políticas e de processos que possam garantir-Ihes o gozo da educação superior como um direito.

${ }^{13}$ Um quintil corresponde a $20 \%$ do total de uma distribuição. O uso dessa metodologia permite a comparação entre proporções na distribuição de uma variável, como a renda dos estudantes da educação superior nos países listados aqui verificados.

Movimento-Revista de Educação, Niterói, ano 5, n.9, p.69-106, jul./dez. 2018. 


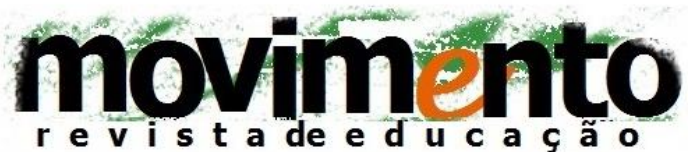 \\ faculdade de educação - programa de pós-graduação em educação \\ universidade federal fluminense \\ issn 2359-3296 \\ ano 5 número 9 - 2018}

O reconhecimento dessas questões na concepção, na implementação, na gestão e na avaliação das políticas públicas de educação tornou-se central para os pesquisadores e para os operadores dessa política pública no Brasil e na América Latina, conforme apontam os trabalhos de Pacheco e Ristoff, (2004), Severino (2009), Vargas e Paula (2013) e Rothen e Silva (2014).

Noções ainda não consolidadas nos estudos; como "novo aluno" (BRITTO, 2005. p. 786), "estudante trabalhador/trabalhador-estudante" (VARGAS \& PAULA, 2013. p. 459) ou "estudante parcial" (ZAGO, 2006. p. 233) tornaram-se presentes na produção do campo educacional e nas reflexões sobre como compreender, como medir e como estudar esse fenômeno e entraram para a pauta dos estudos dos diferentes aspectos das mudanças que geraram uma nova face para a universidade com parte de uma nova dinâmica nas disputas pelo capital cultural (Setton, 2005).

Uma perspectiva oficial brasileira dessa discussão é a tentativa de construção de medidas de eficácia da oferta pelo acompanhamento da trajetória dos estudantes ao longo do curso que levou o Inep a publicar uma metodologia de Cálculo dos Indicadores de Fluxo da Educação Superior.

Não cabe nesse artigo uma análise dessa metodologia, mas é importante que se registre a relação entre as questões afeitas aos temas do acesso e da permanência e uma proposta oficial para tratamento dos dados produzidos pelo censo da educação superior para que se possa compreender, ainda que indiretamente pela análise dos fluxos, os mesmos processos e os mesmos fenômenos. 


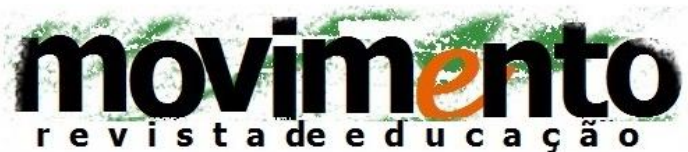 \\ faculdade de educação - programa de pós-graduação em educação \\ universidade federal fluminense \\ issn 2359-3296 \\ ano 5 número $9-2018$}

Espera-se que esse novo tratamento dos dados e essa análise de seus resultados possam auxiliar na formulação de políticas para a educação superior. É importante associar o conceito de fluxo à resolução do problema da permanência na universidade de todos os perfis sociais de discentes para que o desenho das políticas tenha um caráter redistributivo. Se não for dessa forma, apenas se constatará que os mecanismos de produção de desigualdade e de exclusão das pessoas são persistentes e que a política pública não cumpriu o seu papel democratizante.

Resta saber se há preocupação dos operadores das organizações privadas com o acesso e com a permanência dos estudantes. Além disso, interessaria às IES privadas o desenvolvimento de soluções para a permanência dos alunos em seus cursos e nas suas instituições?

Claro que essas questões são relevantes para essas organizações. Entretanto, essa temática é tratada de forma diferente ${ }^{14}$ e com propostas de soluções diversas daquelas em que se defende a universalização da educação pública. Apesar disso, a forma como atuam as instituições particulares sobre essa problemática precisa ser compreendida, estudada e criticada por todos os interessados na política da educação superior no Brasil.

A política pública de educação superior desenvolvida no país nos anos recentes tem sido alvo de críticas por diferentes autores que se dirigem principalmente aos seguintes aspectos:

a) As estratégias de financiamento e os mecanismos utilizados para promover a expansão da oferta.

\footnotetext{
${ }^{14} \mathrm{O}$ tema costuma frequentar os debates entre as mantenedoras e grupos educacionais do setor privado, como evasão de receita potencial estimada de 17 bilhões de reais, segundo cálculos da Consultoria Lobo e Associados em 2016.
} 


\section{movimento \\ faculdade de educação - programa de pós-graduação em educação \\ universidade federal fluminense \\ issn 2359-3296 \\ ano 5 número 9 - 2018}

b) A necessária revisão e o aprimoramento dos instrumentos de controle da política pública de educação superior.

c) As falhas nas metodologias de supervisão das organizações responsáveis pela oferta da educação superior. ${ }^{15}$

Dentre essas críticas, as mais significativas são aquelas que resultam da análise da aplicação da verba pública. Nelas podemos verificar o aparente problema do favorecimento recebido pelos grandes grupos educacionais nacionais e internacionais.

Ainda nesse campo do financiamento da expansão da oferta, essas críticas destacam a assimetria no tratamento dado ao custeio e aos investimentos nas instituições públicas frente às renúncias fiscais e aos financiamentos que favoreceram o setor privado e que podem ter afetado a capacidade do público de alcançar as metas do Plano Nacional de Educação (PNE).

Mazzarotto (2007) lista os quatro objetivos que um sistema de educação superior deveria aspirar a fim de levar o país a um crescimento econômico significante: (1) geração de pesquisa de alta qualidade, (2) geração de pesquisa aplicada e integração com outros pesquisadores e usuários da pesquisa aplicada, (3) produção de ensino de alta qualidade em ambos os níveis: médio e superior e (4) seleção dos melhores estudantes e pesquisadores a fim de perpetuar o sistema.

Vários são os elementos que distinguem o setor público do privado. O primeiro deles é a finalidade da organização, que no caso do setor privado são os ganhos em rentabilidade e em produtividade. $O$ segundo, igualmente relevante,

\footnotetext{
${ }^{15}$ Essas críticas podem ser encontradas especialmente em Mancebo (2004), Taffarel (2004), Rocha (2005), Leher (2005 e 2010), Sguissardi (2008) e Traina-Chacon \& Calderón (2015).
} 


\section{movimento \\ faculdade de educação - programa de pós-graduação em educação \\ universidade federal fluminense \\ issn 2359-3296 \\ ano 5 número 9 - 2018}

é a liberdade formal para agir que tende a ser maior no privado que no público $^{16}$.

Outras diferenças são relativas às formas de administração, tais como: rotatividade de funcionários e de professores baseada em necessidades competitivas conjunturais de mercado; criação de cursos e de modalidades de ensino rápidas a fim de maximizar os ganhos; recrutamento e rotatividade de estudantes com a finalidade de maior lucratividade no curto prazo; avaliação do desempenho de professores de acordo com os interesses dos alunos que são tratados como consumidores; padronização dos currículos e adoção de métodos de controle formal das funções docentes e a implementação de processos com o objetivo de aumentar a eficiência econômica.

Outras análises afirmam que as instituições de ensino superior de capital aberto buscam sempre o máximo de rentabilidade. Essa postura pode representar riscos diretos à qualidade da educação, além de facilitar a relação entre a qualidade do ensino e a rentabilidade, o que sustenta diretamente a atratividade financeira dessas organizações (Gramani, 2008).

Gramani afirma, ainda, que a perda da qualidade do ensino levasse à da atratividade econômica para as organizações. Um negócio com esse formato estaria reduzido a especulações de curto prazo, o que é incompatível com o desenvolvimento econômico sustentável de um país ou mesmo de uma atividade financeira, como demonstra o modelo de Aghion e Cohen apresentado por Mazzarotto (2007).

\footnotetext{
${ }^{16}$ Enquanto no setor público a liberdade para agir depende necessariamente da autorização legal expressa para o ato, no privado, mesmo que haja controle regulatório, qualquer ação pode ser realizada se não houver impedimento previsto em lei.
} 


\section{movimento \\ faculdade de educação - programa de pós-graduação em educação \\ universidade federal fluminense \\ issn 2359-3296 \\ ano 5 número 9 - 2018}

Os processos e os fatores que permitem a uma organização alcançar ganhos em produtividade e em rentabilidade mais listados na literatura administrativa e econômica e aplicados ao setor educacional são:

- Ampliação da escala produtiva;

- Padronização, centralização e automatização de processos recorrentes;

- Redesenho dos cursos;

- Mudanças nas modalidades e nas políticas de cobrança e de bolsas;

- Oferta de disciplinas universais de caráter nivelador;

- Desburocratização no processo de mudança de curso ou de modalidade na mesma instituição;

- Redefinição das atividades docentes ${ }^{17}$.

Ainda segundo Gramani (2008), a relação entre os indicadores de "atratividade econômica" e os de "qualidade da educação" indica quais ações gerenciais estratégicas e operacionais levam à otimização das duas variáveis. A partir delas, percebem-se algumas possibilidades de enfrentamento à questão do acesso e da permanência nesse tipo de organização, como apresentados na figura 2.

O argumento da autora expressa a contradição capitalista, pois, mesmo tendo construído uma argumentação circunscrita aos limites das concepções pró-

\footnotetext{
17 Não foram listados os fatores associados à gestão da força de trabalho que representam verdadeiros ataques em direção à extração de mais-valia relativa e absoluta, tais como sua precarização progressiva, a sobre-exploração produtiva e as implicações, inclusive na saúde, na sanidade dos profissionais docentes, porque foge ao escopo deste trabalho. No entanto, deve ser reconhecido que, nesse período de três décadas, na expansão da oferta de vagas no ensino superior no Brasil, a carreira docente do magistério superior está entre as que sofreram os maiores ataques sobre sua dignidade, pois a visão financista dos CEOs (DiretoresPresidentes) e dos CRHOs (Diretores Executivos de Recursos Humanos) dos grupos educacionais considera que o docente é tão somente uma unidade de custo e não a mola propulsora da qualidade da educação oferecida e promovida. Parte desse debate pode ser lido em Motta e Leher (2017).
} 


\section{movimento \\ faculdade de educação - programa de pós-graduação em educação \\ universidade federal fluminense \\ issn 2359-3296 \\ ano 5 número 9 - 2018}

mercado, ela identifica que um modelo que esteja subordinado à produção de resultados financeiros e afastado da defesa da educação como um bem universal não pode sustentar-se como viável e perene economicamente.

Porém, cabe ressaltar que a luta por uma educação pública de qualidade se orienta por valores mais amplos do que a viabilidade ou a atratividade de um negócio. Ela se orienta na direção de um desenvolvimento socioeconômico baseado na produção de conhecimento novo e inovador que inclua a técnica, a ciência, a tecnologia, a cultura e o desenvolvimento integral dos sujeitos em afeto e compreensão do mundo.

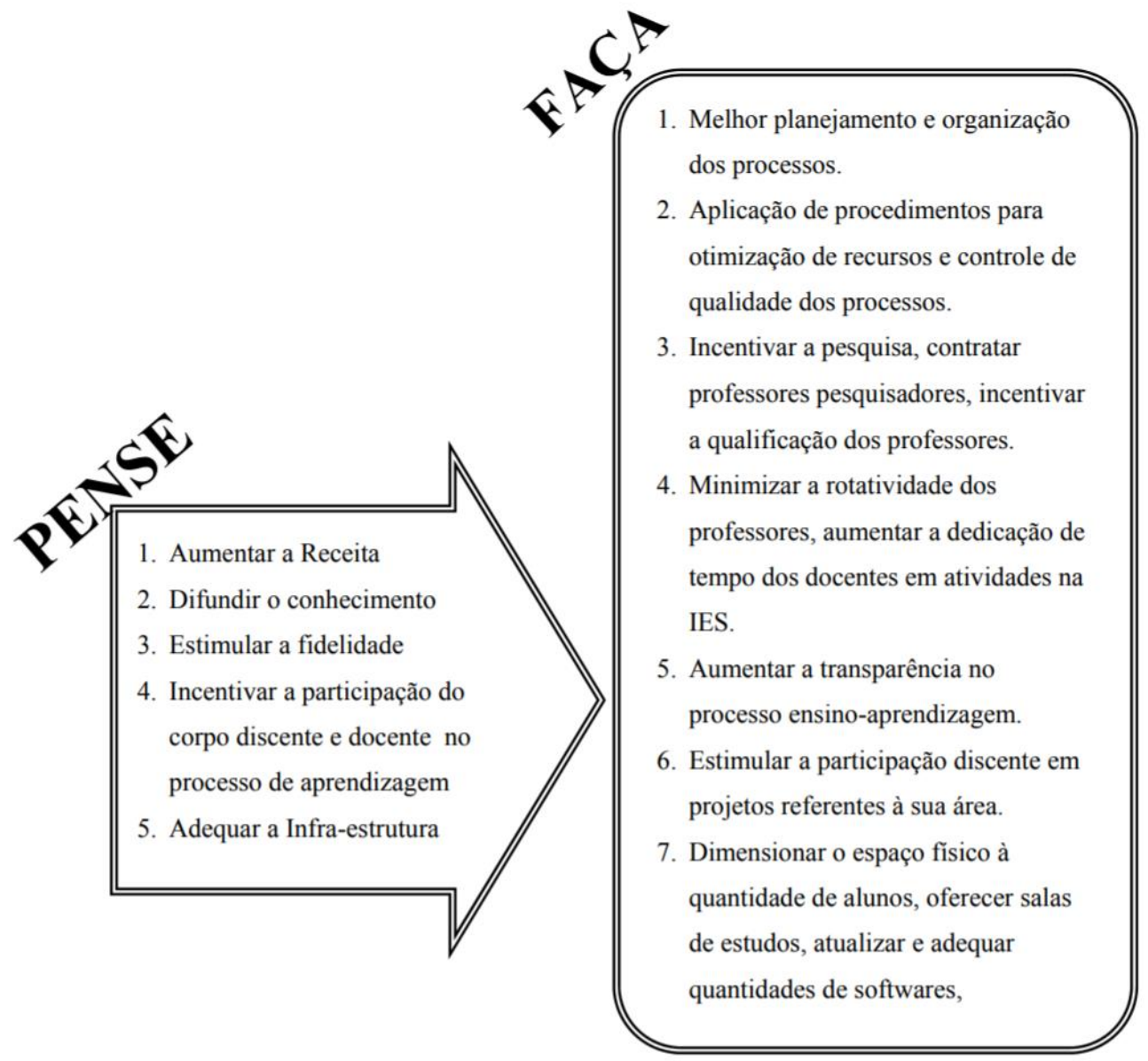

Figura 2: Relação entre objetivos estratégicos e promoção da qualidade da educação no setor privado, segundo Gramani (2008). Fonte: GRAMANI, 2008, p.18. 


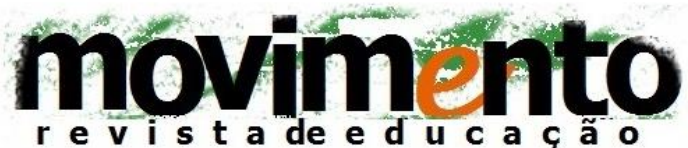 \\ faculdade de educação - programa de pós-graduação em educação \\ universidade federal fluminense \\ issn 2359-3296 \\ ano 5 número 9 - 2018}

Muitas dessas iniciativas podem ter impacto, positivo e negativo, sobre a permanência do estudante no curso ou nas instituições, ainda que, originalmente, não sejam dirigidas primariamente a esse fim. Outras estão diretamente relacionadas à temática da permanência, mas que, no setor privado, assumem outras nomenclaturas advindas do marketing, como retenção e fidelização de alunos.

A literatura sobre a permanência na educação superior relaciona vários fatores sociais, econômicos, pessoais, psicológicos, didático e pedagógicos que afetam a permanência dos estudantes, alguns dos mais recorrentes estão relacionados a seguir:

- Frustrações das expectativas do aluno em relação ao curso ou à profissão;

- Alto déficit entre os conhecimentos acadêmicos herdados do ensino médio e os exigidos no superior;

- Falta de acompanhamento, de orientação e de apoio ao discente ao longo do curso e, especialmente, nos primeiros semestres de estudo, no qual o risco de abandono é maior;

- Baixa oferta de oportunidades de pesquisa, de monitoria, de extensão e de estágio ao longo curso;

- Infraestrutura física do curso deficiente para as necessidades de aprendizagem dos alunos;

- Esvaziamento do poder decisório e da importância dos coordenadores de curso;

- Desenho curricular e metodologias de ensino que não são transparentes para o discente;

- Desenho pouco efetivo para o sistema de acompanhamento psicopedagógico; 


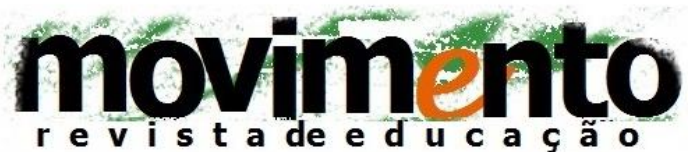 \\ faculdade de educação - programa de pós-graduação em educação \\ universidade federal fluminense \\ issn 2359-3296 \\ ano 5 número 9 - 2018}

- Inadaptação às rotinas de estudo e ao gerenciamento do tempo necessários à educação superior, especialmente na modalidade EaD;

- Condições socioeconômicas desfavoráveis e assistência estudantil insuficiente ou inexistente;

- O verdadeiro "rally" de matrículas novas promovido no setor privado;

- Atrasos no calendário letivo ocasionado pelo prolongamento do período de matrículas de alunos novos, no setor privado, por decisões comerciais e, no público, pelas sucessivas chamadas do Sisu (que oficialmente cessaram depois de 2015);

Nota-se que uma parte importante desses fatores possui possibilidades de ação que permitem intervenção dos profissionais da educação para que se articulem os mais variados processos na composição de um sistema de apoio à permanência no ensino superior capaz de garantir aos estudantes a continuidade e a conclusão dos estudos.

\section{Parte do problema e não da solução?}

O setor privado da educação superior no Brasil responde pela maior parte da oferta de vagas e também pela das estatísticas sobre a evasão. Portanto, nessas instituições, a questão do acesso é resolvida parcial e relativamente pela lógica do mercado (ainda que com financiamento público direto e indireto). Por isso, fica evidente que o problema da permanência do aluno no sistema e da garantia da efetividade e da eficácia do ensino com a conclusão do curso ainda é um problema não equacionado.

A literatura especializada registra a dificuldade do setor privado para manter os níveis de evasão de seus alunos em patamares considerados mais eficazes inclusive nas sociedades desenvolvidas. Nelas, ainda que os índices de evasão 


\section{movimento \\ faculdade de educação - programa de pós-graduação em educação \\ universidade federal fluminense \\ issn 2359-3296 \\ ano 5 número 9 - 2018}

sejam bastantes inferiores aos brasileiros, o tema também está presente nas reflexões dos educadores em países como os EUA.

Algumas universidades norte-americanas, apesar dos altos custos escolares, são as que apresentam as menores taxas de evasão. Isso se deve à promoção de políticas voltadas especificamente para a permanência do estudante. De modo geral, índices de $50 \%$ de abandono no primeiro semestre são comuns nos cursos superiores, especialmente nos colleges ${ }^{18}$ daquele país, o que revela que esse problema também carece de soluções por lá.

Dois elementos que afetam negativamente o desenho de sistemas de apoio à permanência do aluno na educação superior nas diferentes instituições no Brasil. O primeiro, advindo de um cenário menos competitivo por alunos entre as IES privadas, é uma espécie de mentalidade ou de cultura remanescente, herdada de gestores que viveram o período de crescimento do sistema de educação superior anterior ao atual, no qual a demanda reprimida garantia a formação das turmas. Essa mentalidade leva a considerar a evasão apenas como um problema a ser enfrentado pela gestão somente a partir da metade do curso e pode ser expressa no seguinte modelo teórico: ${ }^{19}$

Total de matriculados em um curso hipotético de 8 semestre em um dado período.

$\mathrm{MS}=\mathrm{Mn}+\sum_{p=1}^{8}(\mathrm{RM}(\mathrm{p}+1) * \mathrm{TSn}) \sum_{p=1}^{8}(\mathrm{RM}(\mathrm{p}+1) * \mathrm{TSn}) ;$ onde:

\footnotetext{
18 Instituições de ensino superior que, em geral, oferecem cursos de dois anos, semelhantes às instituições brasileiras que oferecem os cursos superiores de tecnologia e são, quase sempre, orientadas para a formação profissional. Algumas das razões apontadas para evasão são a inadaptação à rotina de estudos no nível superior, as necessidades materiais dos alunos para se dividir entre o trabalho e o estudo e as questões relacionadas ao déficit conhecimentos trazidos da formação em nível médio.

${ }^{19}$ Esse modelo teórico considera ainda que a matrículas novas, nos segundos semestres, de cada ano letivo, sejam $50 \%$ inferiores às dos primeiros, nos oito períodos considerados no modelo teórico.
} 


\section{$\underset{\text { movimento }}{\operatorname{mon}}$ \\ faculdade de educação - programa de pós-graduação em educação \\ universidade federal fluminense \\ issn 2359-3296 \\ ano 5 número 9 - 2018}

MS = Total de matrículas no semestre;

$\mathrm{Mn}=$ total de matrículas novas (primeiro período);

RM $(p+1)=$ Matrículas Renovadas a cada período;

$T_{S n}=$ Taxa de renovação no semestre, que considera uma variação em função do número de semestres cursados, com distribuição em quatro grupos (n):

$\mathrm{T}_{\mathrm{S} 1}$ (do primeiro ao segundo períodos cursados) $=0,6$

$\mathrm{T}_{\mathrm{S} 2}$ (do terceiro ao quarto cursado) $=0,7$

$\mathrm{T}_{\mathrm{S} 3}$ (do quinto ao sexto cursado) $=0,85$

$\mathrm{T}_{\mathrm{S} 4}$ ( sétimo cursado) $=0,9$

O uso de modelos teóricos quantitativos em ciências humanas possui restrições e limitações. Entretanto, o presente modelo foi elaborado a partir da observação empírica da dinâmica da renovação de matrículas em cursos superiores em instituições privadas e pretende apenas testar a hipótese da viabilidade econômica de um curso hipotético de 8 semestres, mesmo em um contexto de baixa renovação de matrículas nos períodos iniciais de oferta.

As fontes do modelo são as taxas de renovação de matrículas, semestre a semestre, esperadas em um ambiente de baixa competição por alunos entre as IES privadas, ou seja, aquele espaço que caracterizou o período anterior a atual fase de concentração financeira nesse setor. As estimativas foram realizadas pela coleta de dados do histórico renovação em IES privadas a que o autor teve acesso.

As taxas de renovação do modelo são consistentes com as observações e com os dados dos censos da educação, em especial a relação entre o total de formandos sobre o de matriculados e de ingressantes. 


\section{movimento \\ faculdade de educação - programa de pós-graduação em educação \\ universidade federal fluminense \\ issn 2359-3296 \\ ano 5 número 9 - 2018}

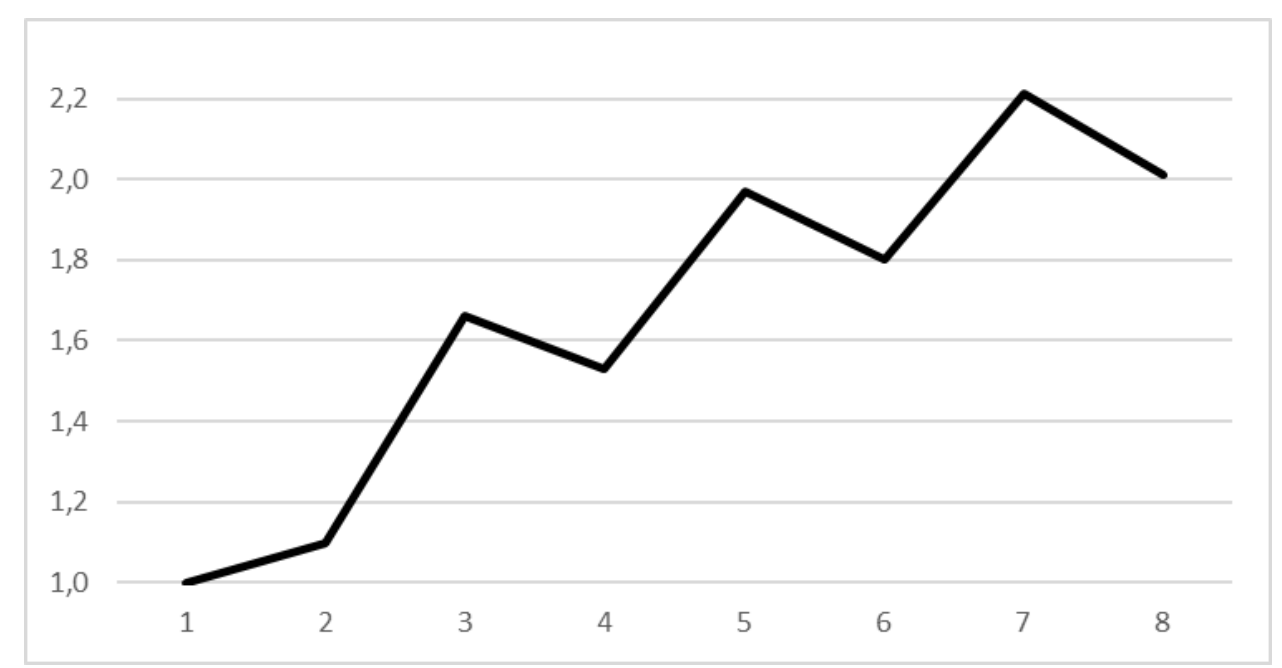

Figura 3: Evolução do total de matrículas, considerando o modelo teórico em 8 semestres. Fonte: Elaboração Própria.

Esse modelo, apesar de simplificado, permite perceber que, aos gestores de um sistema com essas características, ainda que se tenha uma alta perda de alunos ao longo de todo o período (na média $25,71 \%$ entre semestres), a atividade ou o negócio se justificariam, já que o número de matrículas e de renovações, partindo de um índice 1, alcançaria 2,2 em 7 semestres.

Quanto ao tema da permanência e considerando as mesmas premissas no comportamento da renovação das matrículas semestre a semestre, o modelo teórico indica o retratado na figura 4 abaixo: eram esperados que apenas $11 \%$ dos ingressantes concluíssem os estudos ao final dos oito semestres, o que significa que, nessas condições, apesar de viável como "negócio", esse processo seria perverso como mecanismo de inclusão educativa. 

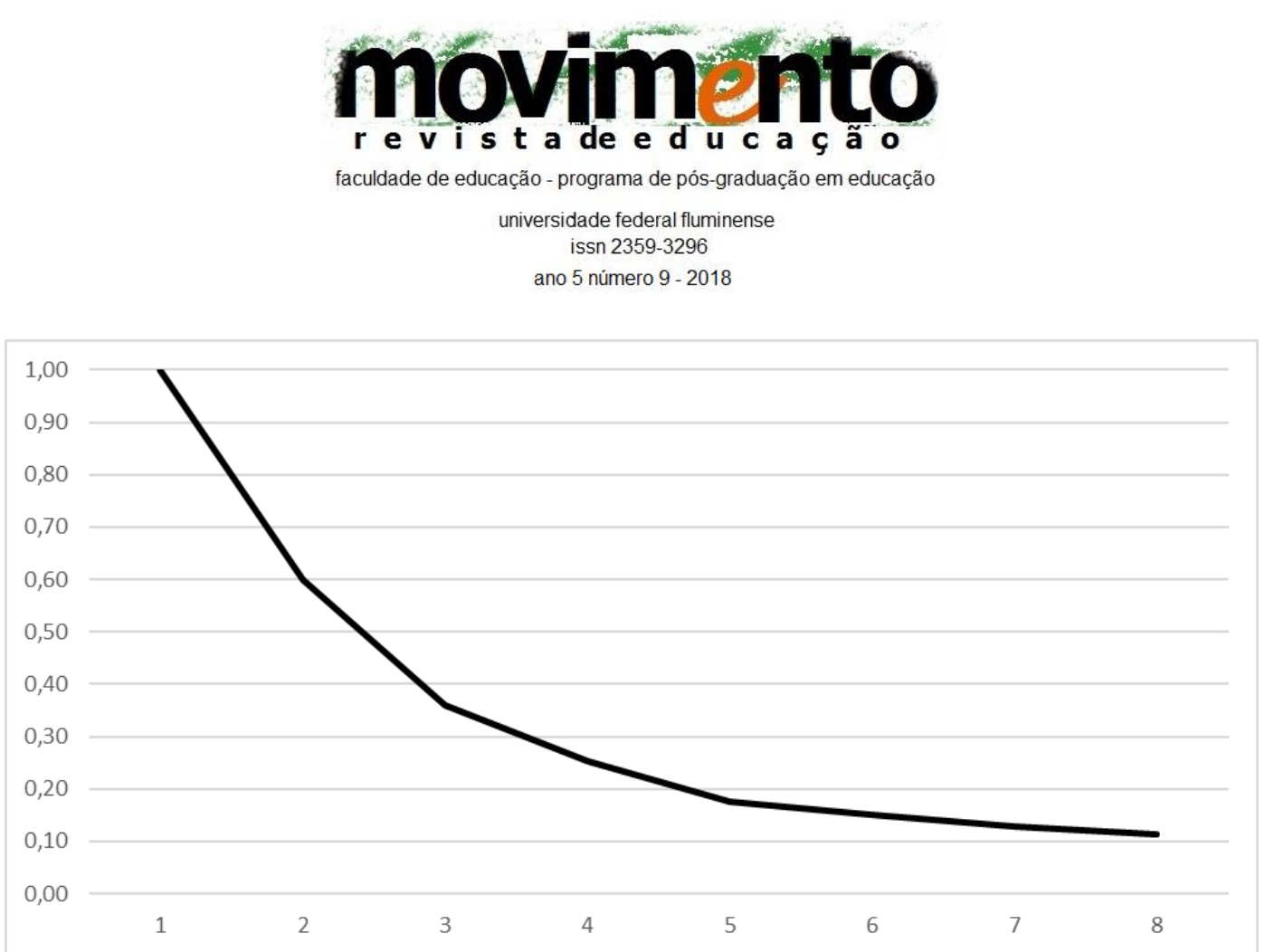

Figura 4: Permanência dos estudantes no curso considerando o modelo teórico. Fonte: Elaboração Própria.

O segundo elemento que pode afetar negativamente a produção de estratégias que visem à permanência do estudante é o valor simbólico da reprovação nos primeiros períodos como "distinção de qualidade" de um curso. Essa é uma cultura muito comum entre coordenadores e professores das áreas de ciências exatas, tecnologia e ciências da terra e de algumas IES privadas de renome.

A reprovação nos primeiros semestres é utilizada como um marketing para a sua "qualidade de ensino" e, dessa forma, não possui preocupação objetiva com a permanência dos alunos, pois só os melhores ficariam até o final dos cursos. A evasão, ao longo dele, é considerada uma espécie de seleção natural promovida pela educação superior.

Por outro lado, soluções para os problemas da evasão e da constituição de mecanismos que favoreçam a permanência dos estudantes na educação 


\section{movimento \\ faculdade de educação - programa de pós-graduação em educação \\ universidade federal fluminense \\ issn 2359-3296 \\ ano 5 número 9 - 2018}

superior estão sendo testadas em várias universidades públicas e privadas, no Brasil e no exterior, pois é grande a relevância da temática. ${ }^{20}$

As alternativas de enfrentamento ao problema têm incluído o uso de metodologias e de recursos tecnológicos avançados como o data mining. Trata-se de um conjunto de técnicas estatísticas e de análise de grande volume de dados que permite construir modelos probabilísticos e elaborar cenários para a tomada de decisão. Há, ainda, instituições utilizando programação com inteligência artificial ${ }^{21}$ sobre os dados dos perfis e de comportamento da rede web e das mídias sociais dos alunos, elaborando e desenvolvendo modelos preditivos $^{22}$ para atuação sobre esses públicos.

Esses modelos preditivos são utilizados, por exemplo, para identificar o risco de um aluno abandonar o curso com base em variáveis como características socioeconômicas, dados de georreferenciamento, notas, tipo de queixas ou solicitações feitas ao curso e reclamações sobre a instituição. Servem também para construção de perfis através de informações comparadas com discentes evadidos ou não - de características semelhantes e para articular estratégias de apoio e de monitoramento.

A constituição de comunidades de cooperação entre alunos e professores para resolução de questões comuns, como as interpessoais ou as de aprendizagem, é outra iniciativa que também vem sendo adotada por IES privadas. A partir de comunidades compostas exclusivamente por alunos (learning peer to peer),

\footnotetext{
${ }^{20}$ Apesar disso, o levantamento feito por Araújo (2013), na base do SCIELO e no Banco de Teses da Capes, entre 1996 e 2011, revela um percentual muito baixo de artigos e teses sobre a temática da evasão ou da permanência no ensino superior.

${ }^{21}$ Esse artigo não se propõe a debater as limitações filosóficas, epistemológicas e tecnológicas que implicam esse conceito. Sobre esse debate, consultar Mccarthy \& Hayes (1981).

22 Modelos preditivos são funções matemáticas aplicadas a um volume grande de dados, que possibilitam compreender um fenômeno complexo, pela identificação de padrões ocultos, em contextos aparentemente caóticos, presentes especialmente em sistemas complexos.
} 


\section{movimento \\ faculdade de educação - programa de pós-graduação em educação \\ universidade federal fluminense \\ issn 2359-3296 \\ ano 5 número 9 - 2018}

forma-se uma espécie de grupo de estudos para ajudar aqueles que têm dificuldade nas disciplinas. Muitas delas estão presentes até nas mídias sociais. Há instituições privadas no Brasil que estão incentivando e gerindo a criação das suas "comunidades do conhecimento" entre os estudantes.

Essas ferramentas orientam as ações da administração e do corpo docente em relação àquele aluno, apoiando-o em suas dificuldades e auxiliando a promoção de estratégias que cooperem com a sua permanência.

Outras IES privadas buscam adaptar o seu repertório gerencial e as suas práticas ao enfrentamento de importantes questões que afetam a educação superior no país. Foca-se sobretudo naqueles problemas com impacto sobre temas sensíveis como a permanência ou a evasão $0^{23}$ de estudantes entre semestres em um mesmo curso ou em uma mesma instituição.

Um exemplo desse tipo de esforço foi apresentado como resultado por uma universidade privada paulista intitulado de Projeto Calouro: Ação Antievasão no Ensino Superior apresentado no seminário "Evasão no Ensino Superior" promovido pelo CRUB em 2015.

O referido projeto desenvolveu um conjunto de atividades que tinham como objetivos:

- Criar no estudante uma sensação de acolhimento;

- Proporcionar experiências que apoiem a transição entre o ensino médio e o ensino universitário;

\footnotetext{
${ }^{23}$ O conceito de evasão admite muitas significações: evasão do curso ou microevasão, evasão da instituição ou mesoevasão e evasão da educação superior ou macroevasão. Existem as diferentes formas de manifestação desse fenômeno (ingressantes que não se matriculam, desistência, abandono, jubilamento), há comportamentos para a evasão (por área de conhecimento, por curso, opção bacharelado ou licenciatura) e de acordo com o perfil do aluno (renda, atividade laboral em paralelo, cuidado com filhos, sexo, idade). Pode variar conforme as etapas do curso (ver GILIOLI, 2016).
} 


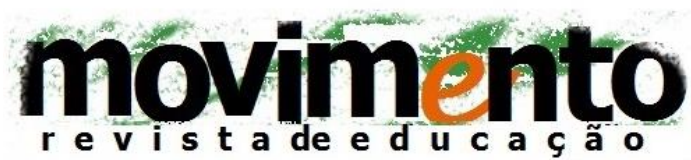 \\ faculdade de educação - programa de pós-graduação em educação \\ universidade federal fluminense \\ issn 2359-3296 \\ ano 5 número $9-2018$}

- Desenvolver habilidades cognitivas, metacognitivas e psicossociais;

- Promover envolvimento e responsabilidade com a aprendizagem;

- Promover senso de protagonismo;

- Aumentar índices de retenção no primeiro período.

Dentre as atividades listadas, havia o acompanhamento do desempenho dos alunos nos estudos até a realização de jogos de integração, a realização de oficinas de uso de mapas conceituais e mentais, o desenvolvimento de estratégias pessoais de aprendizagem e de gerenciamento do tempo e a reflexão crítica sobre expectativas e as realidades do mundo acadêmico.

Uma equipe específica de profissionais foi designada para gerenciar as ações desenvolvidas pelos professores e pelos profissionais da educação com perfil adequado e treinados para desenvolver atitudes de acolhimento aos estudantes nos diferentes campi da instituição.

Os resultados apresentados indicaram uma redução substantiva da evasão do primeiro semestre de 2012 ao segundo de 2014: de 12,3\% para 3,3\%. Entretanto, o relatório não descarta que os resultados possam ter sido influenciados por outras ações empreendidas pela organização em áreas como a de marketing e a comercial.

Outras instituições privadas têm ajustado suas práticas para questões relacionadas à permanência na educação superior. Elas propuseram ações como a Gestão da Base de Alunos com o estabelecimento de metas altas para renovação das matrículas e a captação de novos estudantes. Importante notar que algumas organizações focaram sua expansão no número de discentes no 


\section{movimento \\ faculdade de educação - programa de pós-graduação em educação \\ universidade federal fluminense \\ issn 2359-3296 \\ ano 5 número 9 - 2018}

período chamado crescimento orgânico ${ }^{24}$ (de 2005 a 2009), o que importou em um esforço para reduzir a saída de alunos.

Em um estudo sobre o curso de graduação em engenharia de produção em um centro universitário privado do Noroeste Fluminense, Motta e Gomes (2016) apresentam o trabalho desenvolvido naquela instituição. Nela foi criada uma Equipe de Gestão da Permanência (EGP) que conseguiu, entre os anos de 2011 e 2014, interferir na dinâmica da evasão, reduzindo os indicadores de $28,45 \%$, no primeiro período de $2011 / 2012$, para $15,84 \%$, no terceiro período de 2014/2015, no qual a média anterior era de $29,42 \%$.

Outro ponto no qual a atuação das organizações privadas tem provavelmente afetado a dinâmica da permanência de seus estudantes é no campo das ampliações de suas oportunidades de emprego e estágios. De forma geral, esse serviço é bastante ativo na procura, no estabelecimento de convênios e na disseminação das vagas entre os alunos. As instituições particulares costumam atuar como intermediadores e, em muitas situações, o acesso a uma fonte de renda é o meio que permite ao discente seguir nos estudos.

Os serviços de apoio psicopedagógicos nas instituições privadas são uma das visíveis fragilidades na constituição de sistemas de apoio à permanência dos alunos. Salvo o caso das universidades particulares onde há o curso de psicologia ou o de pedagogia entre aqueles oferecidos, essa ajuda é feita de modo improvisado. Lembramos que esse é um item de avaliação de curso e institucional no modelo do Sinaes.

${ }^{24}$ Aquele que se faz sem aquisição ou fusão de empresas 


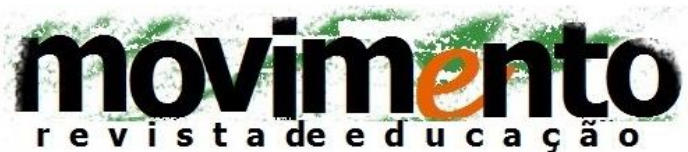 \\ faculdade de educação - programa de pós-graduação em educação \\ universidade federal fluminense \\ issn 2359-3296 \\ ano 5 número 9 - 2018}

\section{Considerações finais}

Como argumenta Washborn (2006), o setor privado se orienta por uma racionalidade oposta à cultura característica da pesquisa acadêmica, na qual o compartilhamento do conhecimento e a autorregulação entre os pares são fundamentais. Esses pressupostos não se ajustam à ideia da propriedade e do segredo comercial típicas do mundo dos negócios.

Apesar de todas as interações entre os agentes privados na distribuição de bens de natureza pública serem críticas e tensas intrinsecamente, em especial as que dizem respeito à educação superior, as características do sistema universitário no Brasil demandam a convivência entre o segmentos público e o privado.

A educação superior no Brasil é um sistema complexo e multifacetado. Ele é composto por diferentes tipos de organizações, de formas de gestão e de mecanismos de financiamento. No entanto, quando pensado do ponto de vista das realidades dos alunos, as distinções de classe, de renda e de etnia não distanciam absolutamente o setor público do privado. Para além dos valores das mensalidades ou da localização das instituições, eles ainda mantêm muitas características em comum (SAMPAIO, 2000).

Criar políticas que garantam a permanência dos diferentes estudantes na educação superior e que correspondam à complexidade do sistema educacional brasileiro envolve considerar a importância dos setores público e privado: é fundamental ponderar a sua abrangência, a sua capilaridade e as suas especificidades ${ }^{25}$.

\footnotetext{
${ }^{25}$ Em ampla medida, esse tema também envolve o debate sobre o financiamento do sistema federal de educação superior e a disputa pela verba pública. No entanto, esse não é o foco do artigo.
} 


\section{movimento \\ faculdade de educação - programa de pós-graduação em educação \\ universidade federal fluminense \\ issn 2359-3296 \\ ano 5 número 9 - 2018}

O setor público tem enfrentado o tema da permanência dos estudantes com mais regularidade, com produção de dados e de estudos relevantes sobre 0 tema. Além disso, tem criado mecanismos de enfrentamento na esfera das instituições e na formulação de políticas públicas.

As organizações privadas também desenvolveram iniciativas para garantir que os estudantes concluam seus cursos. Dentre elas, podemos citar a criação da Equipe de Gestão da Permanência ou o projeto Antievasão. Ainda residual, pontual e pautada nos interesses empresariais, essa ação colabora e coopera com a compreensão de diferentes aspectos do fenômeno, ajudando a construir soluções adequadas.

Essas iniciativas precisam ser mais bem conhecidas, estudadas e avaliadas como algo que pode contribuir para o enfrentamento do problema. É fundamental ter em vista que se trata de um campo de atuação no qual as formas de organização não possuem as características e as rotinas típicas do setor público.

A tradição e a garantia da qualidade da pesquisa no Brasil são da universidade pública. Por isso, um novo programa de pesquisas sobre a permanência de estudantes no ensino superior, com vistas a subsidiar a formulação de políticas públicas de enfrentamento a questão, necessita ampliar o foco dos estudos já realizados e em andamento, abarcando o setor privado.

O incremento dos estudos sobre a permanência no ensino superior no Brasil incluindo sobre o setor privado pode fortalecer as iniciativas existentes e ampliar o entendimento do fenômeno: em primeiro lugar, porque a representatividade atual deste segmento na oferta de vagas e na parcela de 


\section{movimento \\ faculdade de educação - programa de pós-graduação em educação \\ universidade federal fluminense \\ issn 2359-3296 \\ ano 5 número 9 - 2018}

formados a cada ano é significativa, o que indica que qualquer política pública para essa temática somente terá efeitos se envolver as IES privadas.

Segundo, porque uma parcela significativa dos recursos públicos é anualmente comprometida com o financiamento da estrutura atual do sistema de ensino superior, predominantemente privado. Por isso, deixar de construir soluções articulando o setor público e o privado, em suas especificidades, corresponde, na prática, ao desperdício de dinheiro público e, no limite, à reprodução e ao reforço das desigualdades sociais.

Realizar estudos sobre a atuação do setor privado na educação superior não é algo fácil ou corriqueiro. No entanto, é fundamental para um redesenho da educação superior voltado para o desenvolvimento social de um Brasil realmente comprometido com a democratização do acesso e da permanência nessa modalidade de estudo.

\section{Referências}

ANDRADE, Flávio A. Reestruturação Produtiva, Estado e Educação no Brasil de Hoje. Anais, 24 a Reunião Anual da Associação Nacional de Pós-Graduação e Pesquisas em Educação (ANPEd), Caxambu, 7 a 11 de outubro de 2001. Disponível em ANPEd, 25 anos, CD-ROM histórico, 2002.

ARAÚJO, Carla B.Z.M. A permanência de estudantes nos cursos de graduação no Brasil: uma categoria em construção. Revista Temas em Educação, João Pessoa, v.22, n.2, p. 25-43, julho - dezembro, 2013.

ARMSTRONG, Elizabeth A. e HAMILTON, Laura T. Paying for the Party: How College Maintains Inequality. Cambridge: Harvard University Press, 2015.

ARRIGHI, Giovanni. O longo século XX: dinheiro, poder e as origens de nosso tempo. São Paulo: UNESP/Contraponto, 1996.

ATKINSONS, Antony B. Desigualdade: o que pode ser feito? São Paulo: Leya, 2015. 


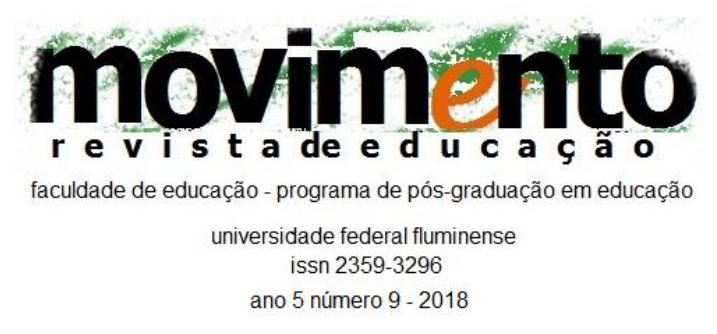

BELL, Daniel. O Advento da Sociedade Pós-Industrial, uma tentativa de previsão social. São Paulo. Cultrix, 1977.

BRITTO, Luis P. L. et alli. Conhecimento e formação nas IES periféricas perfil do aluno "novo" da Educação Superior. Avaliação - Revista da Avaliação da Educação Superior, v.13, n. 3, p.777-791, nov., 2008.

BROCK, Colin e SCHWARTZMAN, Simon. Os desafios da educação no Brasil. Rio de Janeiro: Nova Fronteira, 2005.

CALEFFI, Paula. Universidades S.A.: as companhias de capital aberto da educação superior no Brasil. Rio de Janeiro: FGV editora, 2017.

CORBUCCI, Paulo R.; KUBOTA, Luís C. e MEIRA, Ana P. B. Evolução da Educação Superior Privada no Brasil: da Reforma Universitária de 1968 à década de 2010. Radar, № 46. Brasília: IPEA, ago.2016.

CUNHA, Luiz Antônio. Desenvolvimento desigual e combinado no ensino superior: Estado e mercado. Educ. Soc., Campinas, v. 25, n.88, p. 795-817, out. 2004.

. A universidade temporã: o ensino superior, da Colônia à Era Vargas. 3ª edição. São Paulo: Editora UNESP, 2007.

. O Desenvolvimento meandroso da educação brasileira entre o Estado e o mercado. Educ. Soc., Campinas, vol. 28, n. 100 Especial, p. 809-829, out. 2007.

DAHL, Robert. A. Poliarquia: Participação e Oposição São Paulo: Editora da Universidade de São Paulo, 2005.

FERREYRA, Maria M. et alli. At a Crossroads: Higher Education in Latin America and the Caribbean. Directions in Development-Human Development; World Bank, Washington, DC, 2017. Disponível em https://openknowledge.worldbank.org/handle/10986/26489. Acesso em 13 set. 2018.

GILIOLI, Renato de S. P. Evasão em instituições federais de ensino superior no Brasil: expansão da rede, SISU e desafios. Consultoria Legislativa. Estudo Técnico. Brasília: Câmara dos Deputados, maio 2016.

GRAMANI, Maria C. N. A influência da qualidade na atratividade de instituições de ensino superior com capital aberto. Ensaio: Avaliação e Políticas Públicas em Educação, Rio de Janeiro, v. 16, n. 60, p. 437-454, set. 2008. Disponível 


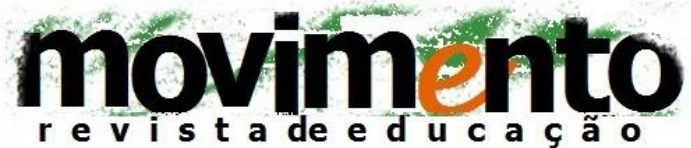 \\ faculdade de educação - programa de pós-graduação em educação \\ universidade federal fluminense \\ issn 2359-3296 \\ ano 5 número 9 - 2018}

em http://www.scielo.br/pdf/ensaio/v16n60/v16n60a07.pdf. Acesso em 30 abr. 2018.

LEHER, Roberto. Universidade no Brasil e na América Latina: tensões e contradições entre o público e o privado. Revista Brasileira de Educação, Rio de Janeiro. v.12, n. 34, p. 171-177, Abril. 2007. Disponível em http://www.scielo.br/pdf/rbedu/v12n34/a15v1234.pdf. Acesso em 30 abr. 2018.

. Crise estrutural e função social da universidade pública. Temporalis.

v.1, p.15-39, 2010.

MCCARTHY, J. e HAYES, P.J. Some Philosophical Problems from the Standpoint of Artificial Intelligence in Readings in Artificial Intelligence. Amsterdam: Elsevier, 1981.

MANCEBO, Deise. Reforma Universitária: Reflexões Sobre a Privatização e a Mercantilização do Conhecimento. Educ. Soc.., Campinas, vol. 25, n. 88, p. 845-866, Especial, Out. 2004.

MAZZAROTTO, Nicola. Competition and Market Incentives in Higher Education. Social Science Reserch Network. Sine Loco. Setembro 2007. Disponível em SSRN: https://ssrn.com/abstract=1059881 ou http://dx.doi.org/10.2139/ssrn.1059881

MOTTA, Marcos P.O. e GOMES, André R. Perda estimada em um curso de engenharia numa IES Privada no noroeste fluminense antes e depois da implantação de uma equipe de gestão da permanência EGP. Revista Interdisciplinar do Pensamento Científico. ISSN: 2446-6778 № 1, volume 2, artigo no 12, Janeiro/Junho 2016. Disponível em:

http://dx.doi.org/10.20951/2446-6778/v2n1a12. Acesso em: 20 abr. 2018.

MOTTA, V. C. e LEHER, Roberto. Trabalho Docente no contexto do retrocesso do retrocesso. Revista Trabalho, Política e Sociedade, v. II, n. 3. p 243-258, 2017.

PACHECO, Eliezer e RISTOFF, Dilvo. Educação superior: democratizando o acesso. Brasília, Textos para Discussão n. 12, Instituto Nacional de Estudos e Pesquisas Educacionais Anísio Teixeira (INEP/MEC), 2004.

PAZ, Sandra R. e Bezerra, Ciro. A fetichização do conhecimento no contexto do capitalismo contemporâneo. V Colóquio Marx e Engels. UNICAMP Campinas, 06 a 09 nov.de 2007. 


\section{movimento \\ faculdade de educação - programa de pós-graduação em educação \\ universidade federal fluminense \\ issn 2359-3296 \\ ano 5 número 9 - 2018}

PRATES, Antonio A.P. e Collares, Ana C. M. Desigualdade e expansão do ensino superior na sociedade contemporânea: O caso do Brasil do final do século XX ao princípio do século XXI. Belo Horizonte: Fino Traço, 2014.

RESUMO TÉCNICO: CENSO DA EDUCAÇÃO SUPERIOR 2015. 2‥ ed. Brasília: Instituto Nacional de Estudos e Pesquisas Educacionais Anísio Teixeira, 2018.

ROCHA, Mirtes A. G. A da. Decifra-se ou te devoro - Decifra-me ou te devoro: discurso e reforma universitária do Governo Lula: um enigma a decifrar. 2005. Tese (Doutorado). Programa de Pós-Graduação em Serviço Social, Universidade Federal de Pernambuco, Recife, 2005.

ROTHEN, José C. e SILVA, Eduardo P. et al. Políticas públicas para a educação superior. São Paulo: Xamã, 2014.

SAMPAIO, Helena M. S. O ensino superior no Brasil: o setor privado. São Paulo: HUCITEC, 2000

SETTON, Maria da G. J. Um novo capital cultural: pré-disposições e disposições à cultura informal nos segmentos com baixa escolaridade. Campinas: Educ. Soc., v. 25, n. 90, p. 77-105, janeiro/abril, 2005.

SEVERINO, Antônio J. Expansão do Ensino Superior: Contextos, Desafios, Possibilidades. Avaliação, Campinas; Sorocaba, SP, v. 14, n. 2, p. 253-266, jul. 2009.

SILVEIRA, Zuleide S. da. Concepções de educação tecnológica na reforma da educação superior: finalidades, continuidades e rupturas (1995-2010) - estudo comparado Brasil e Portugal. Tese de Doutorado. Orientador: José dos Santos Rodrigues. Co-orientador: Belmiro Gil Cabrito. Universidade Federal Fluminense, Faculdade de Educação, 2011. Disponível em https://marxismo21.org/wp-content/uploads/2015/07/TESE-FINAL-ZuleideSilveira.pdf. Acesso em 12 set. 2018.

e BIANCHETTI, LUCÍDIO. Universidade moderna: dos interesses do Estado-nação às conveniências do mercado. Rev. Bras. Educ. [online]. 2016, vol.21, n.64, pp.79-99. ISSN 1413-2478.

SGUISSARDI, Valdemar. Universidade pública estatal: entre o público e privado-mercantil. Educ. Soc. v. 26, n. 90, p. 191-222, jan./abril, 2005.

. Modelo de expansão da educação superior no Brasil: predomínio

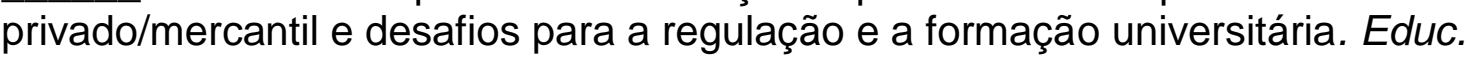
Soc. [online]. 2008, vol.29, n. 105, set./dez. 2008. 


\section{$\underset{\text { movimento }}{\operatorname{mon}}$ \\ faculdade de educação - programa de pós-graduação em educação \\ universidade federal fluminense \\ issn 2359-3296 \\ ano 5 número 9 - 2018}

SOUSA, José V. de. Expansão e avaliação da educação superior brasileira: formatos, desafios e novas configurações. Belo Horizonte: Fino trato/

Faculdade de Educação da Universidade de Brasília, 2015.

TAFFAREL, Celi Z. Morte anunciada: educação superior pública. Universidade e Sociedade. DF, Ano XIV, № 33, junho de 2004.

TRAINA-CHACON, José M. e CALDERÓN, Adolfo-I. A expansão da educação superior privada no Brasil: do governo de FHC ao governo de Lula. Revista Iberoamericana de Educación Superior Volume 6, número 17, 2015.

VARGAS, Hustana M. e PAULA, Maria de F. C. A inclusão do estudantetrabalhador e do trabalhador-estudante na educação superior: desafio público a ser enfrentado. Avaliação: Revista Da Avaliação Da Educação Superior, v. 18, p. 459-485, 2013.

WASHBORN, Jensifer. UNIVERSITY INC.: The Corruption of American High Education. New York. Basic Books, 2006

ZAGO, Nadir. Do acesso à permanência no ensino superior: percursos de estudantes universitários de camadas populares. São Paulo: Revista Brasileira de Educação v. 11, n. 32, p. 226-237, maio/agosto 2006.

\section{Fontes dos dados}

Banco Mundial: https://openknowledge.worldbank.org/handle/10986/26489

CEDLAS/UNLP: $\underline{\text { http://www.cedlas.econo.unlp.edu.ar }}$

INEP: http://inep.gov.br/resumos-tecnicos1

\section{SOBRE OS AUTORES}

MARCO AURELIO NUENES DE BARROS é doutorando em Política Social pela Universidade Federal Fluminense.

E-mail: sociologo.marco@gmail.com

HILDETE PERREIRA DE MELO HERMES DE ARAUJO é Doutora em Economia da Indústria e da Tecnologia pela Universidade Federal do Rio de Janeiro (UFRJ). Professora da Universidade Federal Fluminense.

E-mail: hildete43@gmail.com 


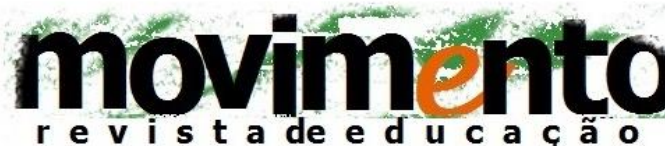 \\ faculdade de educação - programa de pós-graduação em educação \\ universidade federal fluminense \\ issn 2359-3296 \\ ano 5 número 9 - 2018}

Aceito em: 19.09.2018

Movimento-Revista de Educação, Niterói, ano 5, n.9, p.69-106, jul./dez. 2018. 